\title{
An Integrative Design Framework for New Service Development
}

\author{
Eng K. Chew \\ Faculty of Engineering \& IT, University of Technology, Sydney, Australia. \\ eng.chew@uts.edu.au
}

\begin{abstract}
Service innovation is focused on customer value creation. At its core, customer-centric service innovation in an increasingly digital world is technology-enabled, human-centered, and process-oriented. This requires a cross-disciplinary, holistic approach to new service design and development (NSD). This paper proposes a new service strategy-aligned integrative design framework for NSD. It correlates the underlying theories and principles of disparate but interrelated aspects of service design thinking: service strategy, concept, design, experience and architecture into a coherent framework for NSD, consistent with the service brand value. Application of the framework to NSD is envisioned to be iterative and holistic, accentuated on continuous organizational and customer learning. The preliminary framework's efficacy is illustrated using a simplified telecom case example.
\end{abstract}

Keywords: service concept; service design; service architecture; customer experience; new service development; service innovation

\section{Introduction}

With service science maturing and gaining wider acceptance by academics and practitioners alike, a growing interest in the theories and practices of service systems design and implementation $[1,2]$ has emerged, as exemplified by recent work on conceptual frameworks for guiding service systems design [3] and service networks innovation [4]. However, the observations that "the narrowness of much writing on service design" and "the dilemma of service design [as to] whether it is a product or a process that is being designed" have led Voss and Hsuan [5, p.232] to argue for the need to rethink service design from a cross-disciplinary (including marketing, operations and information technology) holistic perspective, in the context of New Service Development (NSD) $[6,7,8]$. However, it remains a knowledge gap in the literature as to whether and how the disparate views of service design seen by marketing, operations and systems experts within a firm could logically be integrated to produce new coherent service designs. This paper contributes to closing this knowledge gap.

This paper pursues the research question: Could an integrative design framework be defined that would integrate the disparate business and technical views of service design into a coherent model that would ensure end-to-end design integrity? In particular, inspired by our initial informal dialogues with practitioners from large and 
new start-up enterprises concerning NSD challenges, the paper seeks to define a new integrative service design framework that will allow cross-disciplinary (marketing, operations and IT) experts in a firm to systematically co-conceptualize, co-design and co-implement new services, in line with the service strategy and brand value, to meet current or emergent customer needs, efficiently and effectively. We conduct an exploratory review of the extant literature and correlate, holistically and integratively, the underlying theories and principles of various disparate but interrelated aspects of design thinking for NSD, namely, service strategy [9, 11], service concept $[9,10,11$, 12], service design $[13,14,11,12,15,16,17]$, customer experience $[16,17,18,19$, $20,21,25]$, and service architecture [5, 26, 27, 28, 29, 30] which hitherto have often been analyzed individually in a somewhat fragmented manner. Using the basic principles and theories of service science, we correlate these different aspects of service design thinking and integrate them into a coherent framework. The efficacy of the framework is illustrated using a simplified telecom NSD case example [30].

The paper is organized as follows. Section 2 reviews the basic service science conceptual building blocks for constructing the proposed integrative service design framework. From the extant literature, the integrative design framework is then synthesized, in Section 3, design aspect by design aspect, with the inter-aspect relationships clearly articulated to ensure conceptual alignment and to minimize design conflicts or contradictions. Then, an exemplar telecom integrative design practice is described, in Section 4, to illustrate a preliminary operationalization of the framework. Finally, Section 5 concludes by summarizing the framework's benefits and limitations; and suggests areas for further study to reduce the limitations.

\section{Conceptual Building Blocks}

\subsection{Process for Capabilities Integration}

A service is defined as a process of applying the competencies and skills of a provider for the benefit of, and in conjunction with, the customer [31, 32]. A service offering is produced using the firm's resources including both tangible (such as goods) and intangible (such as knowledge, competence and relationship) assets [33]. The value characteristics of the service provisioned, however, are co-created through the interactions of the client's competences with that of the service provider [34]. Thus the client is active in a service interaction; it co-creates value (for itself) with the provider by integrating the provider's competences with its own [34, 35, 13]. Therefore, service is about "the process of parties doing things for and with each other, rather than trading units of output, tangible or intangible" [32]. Consequently, from the NSD perspective, service design is about designing the processes to facilitate resource or competence/capability integration by the customer.

A service firm (such as a telecom provider) is conceptualized as a service system [30] which is defined as a complex adaptive system of people, and technologies working together to create value for its constituents [36]. Thus, service innovation by a service system (firm) using NSD must be cross-disciplinary [5] and is only possible 
when the service system (firm) has information about the capabilities and the needs of its clients, its competitors and itself [37].

\subsection{Value Co-creation in a Digital Ecosystem}

In an increasingly digital world, information technologies are "liquefying" physical assets into information resources, and transform a service firm into a value-creating service system in which a constellation of economic actors (customers, suppliers, business partners and the like) are able to seamlessly collaborate to co-create value [38]. So the firm must establish collaborative processes with customers, partners, and employees to engage in the co-creation of value [39]. And the customer is regarded as an operant resource - a dynamic proactive resource that is capable of acting on other resources to create value for itself [32].

Value co-creation and innovation in the digital world would require firms to institute individualized and immediate customer feedback (to and from the customers) to engender customer and organizational learning [40].This requires a new IT-enabled organizational logic which encompasses modular (multi-sourcing) flexibility, frontline (customer learning) focus, IT-enabled individualization and "connect and develop" innovation practices $[40,41]$. In addition, the firm needs new cooperation structures by partaking in global competence clusters and practicing coopetition [40]. This means the service design framework must support selective participation by suppliers, partners and customers in the overall co-design process. And, customer experience design must incorporate customer learning and facilitate two-way feedback between client and provider.

Above all, to be agile and adaptable as they learn of changing customer needs, firms need to develop dynamic operant resources - the dynamic capabilities [42]. The dynamic capabilities allow firms to continually align their competences to create, build and maintain relationships with (thus the value propositions to) customers (the ultimate source of revenue) and suppliers (the source of resource inputs). Thus, the service design framework must institutes agile organizational and customer learning to sustain the service system's (firm's) dynamic capabilities and thus its evolutionary fitness.

\subsection{Customer Centricity for Service Excellence}

Customer is at the heart of value creation and service is about relationship with the customer [43]. The customer interacts with the service provider via the interface through which information /knowledge, emotions and civilities are exchanged to cocreate value [34]. Value is wholly determined by the customer upon, and in the context of, service usage (and resultant customer experience), in which the competence of the provider is integrated with the competence of the customer to (perform 'a job' to) create (business) value with the customer [32, 43]. To win the service game, the value proposition must consistently meet the customer expectations and behavioral needs [20]. This can be assured by co-opting the customer competence in co-creating the service offering with the provider [44] - e.g. user toolkits for innovation [45]. However, the customer would collaborate with the provider in co-creation of core service offer- 
ings (in the context of service conceptualization and design practices) only if they would gain benefits, such as: expertise, control, physical capital, risk taking, psychic benefits, and economic benefits [19]. The service design framework must therefore support the potential for engaging customers in service offering co-conceptualization, service co-design and customer experience experimentation.

\section{Proposed Integrative Service Design Framework}

To create new innovative services that sustainably co-create superior customer value in the constantly evolving digital ecosystem, an integrated design framework is proposed. It is synthesized from the extant literature in accordance with the preceding conceptual building blocks. First and foremost, the proposed integrated design framework is founded on (Step 0 in Figure 1) the firm's mission and service strategy focused on meeting the customers' existing and emerging needs. In particular, the firm's brand value and its subordinate service value proposition must resonate and align with the customers' requirements (or value expectations).

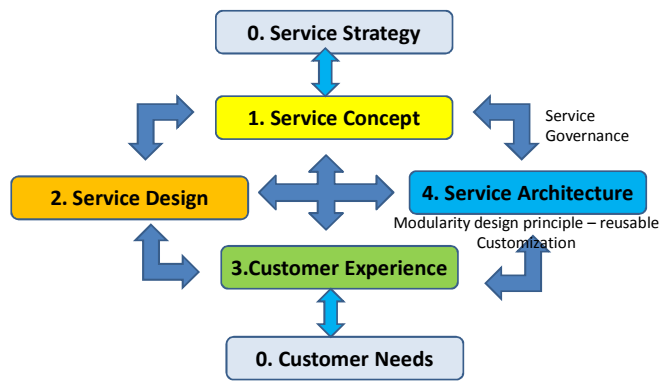

Figure 1: An Integrative Service Design Framework

The integrative design framework for NSD (see Figure 1) consists of closely interrelated practices of: (a) service concept which defines what the service is and how it satisfies customer needs [9, 10, 11, 12], (b) service design which defines the service delivery mechanisms to consistently satisfy customer needs [13, 14, 15, 16, 17], (c) customer experience and value creation which guides service design to align the provider's competences and learning regime to those of the customers to ensure superior experience [16, 17, 18, 19, 20, 21, 22, 23, 24, 25], and (d) service architecture which systematizes service concept, service design and innovation [5, 26, 27, 28, 29, 30]. These four interrelated practices and their underlying theories and principles are detailed below individually, but are typically practiced in the real-world iteratively and holistically - accentuated on agile organizational and customer learning for each and every iterative step such that the integrated design practice becomes the firm's dynamic capability enabling it to attain evolutionary fitness with the turbulent external market environment [42]. 


\subsection{Service Strategy}

Strategy (Step 0) is designed to fulfill the firm's vision and mission. There is a fourstep approach to developing a successful service strategy: (1) Select the innovation focus, such as new service innovation or service delivery innovation, and the target customer group(s); (2) Uncover customer needs in terms of jobs to get done and outcomes expected; (3) Prioritize customer needs; (4) Develop a service strategy (and attendant service concept) to fulfill the high priority customer needs [9]. A successful service strategy fits what the customer will value with what the company can deliver. This means aligning the service concept (what it would take to deliver on the customer value propositions), and hence the service architecture, with firm's capabilities, resources, culture and strategy.

\subsection{Service Concept}

A service concept (Step 1) defines the conceptual model of the service. It describes what the service is and how it satisfies customer needs [9]. Service concept is the most critical component of service strategy, and reflects the alignment of the customer needs (job and outcome opportunities) with the company capabilities. It reinforces the firm's brand strategy/value. Service concept also forms the fundamental requirements for service design, service development and service innovation [10]. It is developed as the end-result of the activities of strategic positioning, idea generation and concept development/refinement - a marketing-led cross-disciplinary endeavor. The conceptual model of a service consists of seven components which together define the desired customer outcomes (value propositions) of the service: service benefits, participation activities, emotional component, perception component, service process, physical environment, and people/employee [10]. To define an innovative service concept, Bettencourt [9] recommends that a service firm should: focus creative energies on specific job and outcome opportunities; identify where the key problems lie in satisfying highopportunity jobs and outcomes; systematically consider a diverse set of new service ideas to satisfy the opportunities; and build a detailed concept with service strategy and service delivery in mind.

Service concept is the principal driver of service design decisions at all levels of planning and implementation. It relates to service architecture or service blueprint which guides service design, and to service governance which defines the decision rights and the decision making process for service design, planning and implementation [11]. For example, at the strategic planning level (marketing-led), the service concept drives design decision for new or redesigned services. At the operational level (IT/operations-led) it defines how the service delivery system implements the service strategy and how to determine appropriate performance measures for evaluating service design. At the service recovery level (operations-led), it defines how to design and enhance service encounter interactions. Thus service concept along with the overarching service architecture is the common foundation for new service development, service design and service innovation. For instance, service concept development and test- 
ing is at the heart of service design in new service development. Central to service conceptualization is declaring what the customer value proposition is in relation to the firm's strategic intent, how it meets the customer needs and what is the service logic required in delivering the value proposition [11]. Service concept articulates the service operation - why and how the service is delivered (in line with the brand value); the service experience - i.e. customer experience; the service outcome - i.e. customer benefits; and the service value - i.e. the perceived customer benefits minus the service cost [12]. Service concept and the corresponding service design (described below) are intended to reflect the service firm's business strategy and brand value, and therefore directly impact the firm's financial performance.

\subsection{Service Design}

Service design (Step 2) - an IT/operations-led cross-disciplinary endeavor - starts with the customer/user and defines how the service will be performed using human-centered and user-participatory methods to model the service performance [15].

We distinguish service design at two levels: new service development (NSD) at the individual service offering level (akin to new product development in manufacturing), and service system at the service firm level (akin to enterprise design).

From NSD perspective, a service is conceptualized as an open system with customers being present everywhere. Service design must address strategic service issues such as marketing positioning and the preferred type of customer relationship, in line with the strategic intent of the service organization. Service governance is also required to monitor the service qualities and financial performance against the design outputs. The framework for designing the service delivery system must address multiple interrelated factors: standardization; transaction volume per time period; locus of profit control; types of operating personnel; types of customer contacts; quality control; orientation of facilities; and motivational characteristics of management and operating personnel [11]. The service delivery system fulfills the firm's strategic service vision and is designed / specified by means of service blueprinting [16, 18]. Service blueprinting is a map or flowchart of all the transactions constituting the service delivery process. The map identifies: the potential 'fail-points'; the line of interaction between client and provider known as service encounters; the line of visibility - above it employees actions are visible to the customer (directly affecting customer experience); below it is the 'back-stage' ; and the internal line of interactions below the line of visibility $[16,18]$. The service encounter design is a critical element of service design, because from the customer's viewpoint "these encounters ARE the service" [16]. The design focuses on maximizing the quality of 'service experience' by the customer. However, service experience is the result of the combined efforts of the 'back stage' information and processes and the 'front stage' customer handling - both must work seamlessly in unison in satisfying the customer request [17].

Taking an end-to-end view of service process allows designers to analyze the stakeholders' requirements, pain points and performance metrics from which service design (or redesign for an existing service) could be developed in collaboration with the stakeholders (including suppliers and partners) incorporating a combination of 
changes across process, organization, technology, and tool in an integrative manner [14].

NSD service design must include strategies for handling service variability to ensure sustained level of service quality expected by customers [17]. For instance, to manage an unexpected deviation from normal service encounter, the service design (per service strategy and governance) may incorporate the notion of service personnel 'empowerment' which grants them the discretion to recover from service deviation (failure) by offering 'compensations' or alternative solutions to the customer to minimize adverse impacts to the customer [38]. Moreover, where multichannel services are provided, the design must ensure consistent service experience across all channels. Finally, service design needs to incorporate the requirements of lean consumption by the customers [21] (in accordance with the customer experience design principles described in the next section) and achieve the objectives of service profit chain [46].

At the service firm level, service design is concerned designing the service system (which offers the service) - akin to enterprise or organization design - to achieve the firm's mission and strategy, a C-level executive-led cross-disciplinary endeavor. Service system design must address the roles of people, technology, shared information, as well as the role of customer input in production processes and the application of competences to benefit others. Consequently, it will influence the design of service delivery system for each service offering created by NSD. This design interrelationship will be managed through the modularity principles of the attendant service architecture (see later). The design must also address the service systems' requirements for agility and adaptability in alignment with their environments [36]. A learning framework is necessary to sustain the firm's creative design ability, and improve and scale the service systems. The framework is designed to achieve three critical requirements: effectiveness - the right things get done; efficiency - things are done in the right way; sustainability - the right relationships exist with other service systems to ensure the system's long term sustainability [36, 37]. Sustainability is achieved through the service system's (brand) reputation, because excellent reputations naturally attract value propositions from other service systems wanting to co-create value. It also requires appropriate amount of shared information to be available to all service systems (the principle of information symmetry) to enhance coordination and mutual sustainability within the service ecosystem. The design is however inherently challenged by the people factor, as people are complex and adaptive.

In sum, service system design, broadly, must address four variables: physical setting; process design - the service blueprinting or mapping which designs 'quality' into the service delivery system; job design - the social technical job design which include addressing the employee motivational requirements; and people - the staff (competence) selection [11].

\subsection{Customer Experience}

Service design excellence strives to achieve superior customer experience (Step 3), where the design practice is focused on the usability and pleasurability of the service interactions [25, p.84]. Service organizations are increasingly managing customer experiences to promote differentiation and customer loyalty. Due to its strategic significance as a competitive differentiator, this specialist design practice, whilst being an 
integral part of service design, is factored out as a crucial step deserving special attention in the overall design framework. Customer experience requirements of each service type are usually analyzed using use-case scenarios similar to that of service blueprint $[16,22]$.

Customer experience is influenced by the service intensity, which is defined in terms of the number of actions (frequency and sequence) initiated by the service provider, or the amount (and importance) of information exchanged in a service encounter or the duration of the service encounter $[17,25]$. The service design of multi-interface system must unify service management, human computer interface, and software engineering perspectives into an integrated design embodying the customer experience requirements [22]. The experience-centric service providers design the activity and context of the experience to engage customers in a personal, memorable way.

Customer experience is contingent on the efficacy of service encounter design, which in turn is guided by the possible relationships between the three parties in the service encounter: the service organization (whether to pursue a service strategy of efficiency (cost leadership) or effective (customer satisfaction) or both); the contact personnel (following strict rules/order or empowered with autonomy and discretion); and the interaction between contact personnel and the customer (balancing conflicting "perceived control" by both parties) [13]. Technology could be designed to assist, facilitate, mediate or generate the service encounter, each with a different customer role in the service delivery process $[13,47]$. Technology design therefore must account for potential customer (as well as employee) reaction so as to avoid future problems of acceptance [18].

The customer experience design must also address the complete "customer journey" (from presale, purchase, usage to expiry) and the attendant dynamic engagement process with the service firm [50]. The engagement can be emotional, physical, intellectual, or even spiritual, depending on the level of customer participation and the connection with the environment [23]. The experience is influenced by the effectiveness of value co-creation between the provider and beneficiary - measured by a composite of benefits (utility) and burdens (costs) [18]. Burdens relate to the service's usability or the degree of customer efficiency in 'consuming' the service [21, 48]. Thus, the most compelling service with the best "value for money" to the client is one that has the largest "benefit-to-costs" ratio. Service firms must therefore "consider not only the employees' productivity but also the 'productivity' and experience of the customer." $[18,19,20,21]$ From a service system viewpoint, customer value, created as a result of integrating the provider's resources with the client's, increases the client system's adaptability and survivability to fit with its changing environment [49].

Customer value creation process is a dynamic, interactive, non-linear and often unconscious process [24]. It is culminated from the customer's cognitions, emotions and behavior during the relationship with the provider, across the entire customer journey [50]. Value co-creation is determined in the context of the customer's resource (and capability) integration practice. To achieve optimal value, the customer processes, the supplier processes and the interfacing service encounter processes must all be aligned [24]. The process design must be congruent with the overall service architecture (see next section) to ensure consistent experience across all services and all channels (and devices). 


\subsection{Service Architecture}

Service architecture is conceptualized to systematize service design and innovation. Leveraging concepts from product architecture, service architecture aims to create a common language across different views on service design and a systematic way to operationalize and measure the degree of service architecture modularity [26]. For a new start-up service firm, service architecture practice is likely to be non-existent (or immature). Service architecture capability emerges as the firm becomes more stable financially and growth is accelerating. It culminates in becoming a dynamic organizational capability. For mature firms service architecture features centrally as a reference framework for design governance (to assure customer-effectiveness and efficiency of all new services).

Service architecture is constituted in accordance with the principle of modularity, which in turn is characterized by five dimensions: components and systems as the basic modular units, the interfaces, degree of coupling, and commonality sharing between components, and platform as the overarching configuration of components and interfaces that make up the service architecture [27]. Modularity refers to the degrees by which interfaces between components are standardized and specified to allow for greater reusability and sharing of (common) components among service families. It provides the basis for mixing and matching of components to meet the masscustomization requirements; yields economies of scale and scope, and can help structure services to facilitate outsourcing. Platform strategies are the vehicles for realization of mass customization [27]. As platform decisions often cut across several service lines or divisional boundaries, platform strategic decisions must belong in the top management team who need to and can resolve cross-functional conflicts to jointly-achieve the firm overall strategy.

An important and challenging aspect of service architecture is the interface. Interfaces in services can include people, information, and rules governing the flow of information. Service interface can also include the flow of people. In general, an active role in service customization would be played by both the front-end employees and the customers themselves. This would suggest the service components need to be more loosely coupled than product components [28].

A service system can be analyzed, for the purposes of service architecture, in terms of four levels of increasing details in specification: industry level, service company/supply chain level, service bundle level, and service package/component level [26]. At level 0 , the industry architectural template defines the value creation and the division of labor as well as value appropriation and the division of surplus or revenue among the different players. (This is the financial or commercial view of service design that is seen from the Chief Executive Officer/Chief Financial Officer level.) At level 1, the service company and its supply chain(s) are modeled both upstream and downstream. Both shared (internal cross-functional) and outsourcing of service components are important consideration for the service company level for economic and resource flexibility reasons, in line with its business strategy. (This is the operations management view of service design that is seen from the Chief Operating Officer level.) At levels 2 and 3, the service concept and service design activities of service innovation practice are harmonized and integrated to assure service agility. (This is the Chief Marketing Officer and Chief Information Officer view of detailed service design, 
operational and management levels.) At level 2, the individual service bundles of the service offering at the company level are analyzed - each bundle is viewed as a set of modules of service delivery, comprising the front- and back-office functions (and associated capabilities). The front-office design must comply with the above-mentioned customer-provider service encounter process design principles to ensure superior customer experience and optimal value creation (see section 3.4 Customer Experience). At level 3, the service package and component level, the characteristics of the building blocks (components) are specified that contribute to the overall systems architecture, namely: standardization, uniqueness, degree of coupling and replicability [26]. Thus, service architecture enables service agility as new services can be designed and provisioned with minimal cost and little internal change, and the architecture can be dynamically adapted in response to external stimuli. But this would require support by a corresponding modular organizational architecture as well as IS architecture [26].

\section{Exemplar Integrative Service Design Practices}

Telecom companies (telcos), like banks, compete on customer service (experience) differentiation. Their missions, strategies and brand values are highly customercentric which, through disciplined strategic alignment, strongly influences the ways their services are conceptualized, designed and operationalized.

A simplified telecom service system can be conceptualized as shown in Figure 2. The telecom service system is composed of four service system entities (SSEs): the service provider SSE in collaboration with its IT supplier SSE and network supplier/partner SSE delivers telecom service offerings to its customer SSE. The telecom service provider SSE consists of a collection of network- and systems-capabilities that together with the resources or capabilities of its partners and suppliers are configured (by service design) to create a differentiated service offering (composed of an internally-standardized set of "service encounter" capability components/bundles: fulfillment, assurance, billing and in-service usage) for the customer SSE.

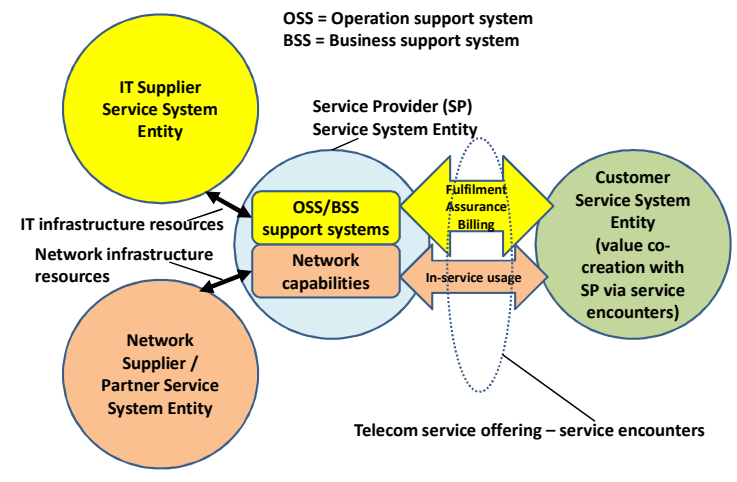

Figure 2: A Simplified Telecom Service System (Adapted from [30]) 
We illustrate below an exemplar application of the proposed integrative service design framework to telecom NSD based on this telecom service system model.

In Step 0, telecom business executive defines the competitive service strategy, often founded on customer intimacy value discipline [51], which is purposefully designed to satisfy the emerging or unmet needs of the chosen (existing and new) customer segments.

In Step 1, the product (marketing) manager informed by deep customer insights envisions and defines a new service concept (supported by operations and IT) - e.g. education institutions' emerging need for a virtual classroom service (in support of an innovative remote education service). This new service would allow geographically separated students from anywhere to participate in a real-time lecture from their home or office, using any device over any network of their choice, while still experiencing the same level of intimate interpersonal interactivity as if they were co-located in the classroom. At the service concept level, the focus is on conceptual (functional) requirements for the utility, usability and pleasurability (including exception handling) of the proposed service concept.

In Step 2 service design, IT and network experts will design (supported by marketing and operations) the integrated network and systems solution that satisfies the service concept requirements. Using the service architecture (Step 4) as a reference framework to leverage service component reusability and ensure the solution's fitness with the telco's overall portfolio of services, the IT/network experts may design, on one hand, a quadruple-play service solution (for "in-service usage" - see Figure 2), combining broadband, mobile, IPTV and multi-media contents in an integrated service delivery (by configuring the appropriate network capabilities in collaboration of network partners/suppliers - see Figure 2); and, on the other hand, design the appropriate accompanying customer "service encounter" capability components of fulfillment, assurance and billing (by configuring the OSS/BSS systems capabilities - Figure 2) ensuring end-to-end service integrity in line with the espoused customer service strategy (Step 0) and the attendant customer experience criteria (Step 4).

In Step 3, customer experience design is typically led by systems designers with human factors engineering expertise [52] who are skillful in designing service encounter interfaces to satisfy the customer's cognitive, emotive and behavioral requirements. Customer experience design is focused on crafting pleasurable (often technology-facilitated) customer interactions (touch-points) with the "service encounter" capability components: fulfillment, assurance, billing and usage throughout the end-to-end customer journey [50] with the telecom provider. Customer experience design effectiveness is linked to the measure of Net Promoter ${ }^{\circledR}$ Score and consequently to firm's financial performance [52]. This entails aligning the end-to-end service encounter processes $[24,50]$ as well as the alignment of service capabilities between the provider and the customers to enhance the experience and productivity of each customer in using the said service [18, 19, 20, 21].

In Step 4, the firm-specific service architecture is used as a reference model for governing the overall aforementioned service design practices. Telecom service design depends critically on the designer's understanding of the provider's service process (the OSS/BSS systems and digital network capabilities - Figure 2) to ensure effective value co-creation accompanied by excellent customer experience. To that end, the telecom industry has specified a standard framework of telecom service pro- 
vider business processes, known as eTOM (enhanced Telecommunications Operations Map) [29]. The eTOM reference framework has been adopted as generic telecom service architecture, Figure 3, and can be used to specify firm-specific service processes, and to source commercial-off-the-shelf standards-based OSS/BSS software systems to support and, where appropriate, automate the specified service processes (business operations such as fulfillment, assurance and billing) [30].

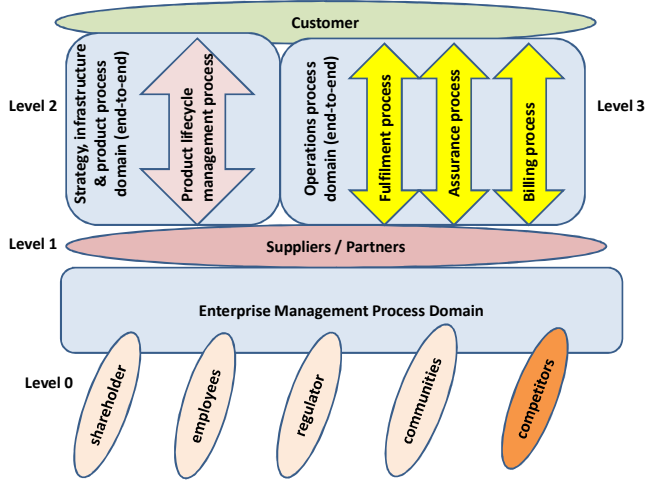

Figure 3: Telecom Service Architecture (Adapted from [30])

\section{Conclusions and Future Work}

Service innovation is focused on creating customer value. Customer co-creates value with the provider by integrating their competences/capabilities with those of the provider. Thus customer productivity is as important as that of the provider in service provision as it impacts directly the service experience. At its core, customer-centric service innovation in an increasingly digital world is technology-enabled but more human-centered and process-oriented. This calls for research into whether and how cross-disciplinary holistic approach to service design would facilitate new service development and innovation.

This paper has used service science principles and theories to reexamine the different aspects of service design from the literature to explicate their logical and conceptual interrelationships. It results in a proposed new integrative service design framework which enables systematic joint service conceptualization, design, architecture and innovation, by cross-disciplinary experts from business, operations and IT. The strategy-aligned framework comprises four closely interrelated practices of: (a) service concept which defines what the service is and how it satisfies customer needs, (b) service design which defines the service delivery mechanisms to consistently satisfy customer needs, (c) customer experience and value creation which guides service design to align the provider's competences and learning regime to those of the customers to ensure superior experience and (d) service architecture which systematizes service concept, service design and innovation. These four interrelated practices are typically practiced in the real-world iteratively and holistically - accentuated on agile organiza- 
tional and customer learning for each and every iterative step such that the integrated design practice becomes the firm's dynamic capability enabling it to attain evolutionary fitness with the turbulent external market environment.

The efficacy of the proposed integrative service design framework has been preliminarily validated by applying it to an exemplar telecom NSD in which telecom service environment is modeled as a service system. More case examples from diverse industries, however, need to be developed to fully validate the industry-wide applicability of the framework and to refine and improve its theoretical soundness.

Service innovation commercialization is contingent on careful alignment of the firm's service strategy, service design and business model design. The proposed framework could therefore be further extended by incorporating business model design principles in the overall service design thinking. We envision the enhanced framework would facilitate rapid business model experimentation of any new service concept to test its commercial viability before committing capital on the comprehensive detailed design process. Learning from our initial analysis of this conceptual extension shows promising potential. Plan is afoot to advance our preliminary knowledge of an integrative service design framework to the next level of theoretical and practical maturity.

\section{References}

1. H. Demirkan, J. C. Spohrer and V. Krishna [Eds.], Science of service systems, Service Science: Research and Innovations in the Service Economy. Springer, Boston (2011)

2. H. Demirkan, J. C. Spohrer and V. Krishna [Eds.], Service systems implementation, Service Science: Research and Innovations in the Service Economy. Springer, New York (2011)

3. Y-H. Tan, W. Hofman, J. Gordijn and J. A. Hulstijn, Framework for the Design of Service Systems. In Demirkan, H., Spohrer, J. C. and Krishna, V. [Eds.], Service systems implementation, Service Science: Research and Innovations in the Service Economy, pp.51-74. Springer, New York (2011)

4. R. Agarwal and W. Selen. An Integrated View of Service Innovation. In Demirkan, H., Spohrer, J. C. and Krishna, V. [Eds.], Service systems implementation, Service Science: Research and Innovations in the Service Economy, pp.253-274. Springer, New York (2011)

5. C. Voss and J. Hsuan. Service Science: The Opportunity to Re-think What We Know about Service Design. Demirkan, H., Spohrer, J. C. and Krishna, V. [Eds.], Science of service systems, Service Science: Research and Innovations in the Service Economy, pp231-244. Springer, Boston (2011)

6. I. Alam, "Removing the fuzziness from the fuzzy-end of service innovations through customer interactions," Industrial Marketing Management, vol. 35, issue 4, 468-80 (2006)

7. B. Edvardsson, A. Gustafsson and B. Enquist, "Success factors in new service development and value creation through services," in D. Spath and K-P. Fahnrich (Eds), Advances in Services Innovations, 166-183 (2007)

8. B. Edvardsson and J. Olsson, "Key concepts for new service development," Service Industries Journal, vol. 16, issue 2, 140-164 (1996)

9. L. A. Bettencourt, "Service innovation: how to go from customer needs to breakthrough services," McGraw-Hill, New York, (2010)

10. B. Fynes and A. M. Lally, "Innovation in services: from service concepts to service experiences," in B. Hefley and W. Murphy (Eds.), Service Science, Management and Engineering Education for the $21^{\text {st }}$ Century, Springer, 229-333 (2008)

11. S. M. Goldstein, R. Johnston, J. Duffy and J. Rao, "The service concept: the missing link in service design research?" Journal of Operations Management vol. 20, issue 2, 121-134 (2002) 
12. G. Clark, R. Johnston and M. Shulver, "Exploiting the service concept for service design and development," in J. Fitzsimmons and M. Fitzsimmons, (Eds.), New Service Design. Sage, Thousand Oaks, CA, 71-91 (2000)

13. J. A. Fitzsimmons and M. J. Fitzsimmons, Service Management: Operations, Strategy, Information Technology. Seventh edition, McGraw-Hill Irwin, New York, NY, (2010)

14. P. P. Maglio, S. Srinivasan, J. T. Kreulen and J. Spohrer, "Service systems, service scientists, SSME and innovation," Communications of the ACM, vol. 49, issue7, 81-85 (2006)

15. S. Holmlid and S. Evenson, "Bringing service design to service sciences, management and engineering," in B. Hefley and W. Murphy (Eds.), Service Science, Management and Engineering Education for the $21^{\text {st }}$ Century, Springer, 341-345 (2008)

16. M. J. Bitner, A. J. Ostrom, and F. N. Morgan, "Service blueprinting: a practical technique for service innovation," California Management Review, vol. 50 , issue 3, 66-94 (2008)

17. R. J. Glushko and L. Tabas, "Designing service systems by bridging the "front stage" and "back stage"," Information Systems, E-business Management, vol. 7, 407-427 (2009)

18. J. A. Fitzsimmons and M. J. Fitzsimmons, Service management: Operations, Strategy, Information Technology. Sixth edition, McGraw-Hill Irwin, New York, NY, (2007)

19. R. F. Lusch, S. L. Vargo and M. O'Brien, "Competing through service: insights from service dominant logic," Journal of Retailing, vol. 83, 5-18, (2007)

20. B. Schneider and D. E. Bowen, "Winning the service game," in P. P Maglio, Kieliszewski and J. C. Spohrer (Eds.), Handbook of Service Science, Springer New York, $31-59$ (2010)

21. J. P. Womack and D. T. Jones, "Lean consumption," Harvard Business Review, 58-68, March (2005)

22. L. Patricio, R. P. Fisk and J. F. Cunba, "Designing multi-interface service experiences: the service experience blueprint," Journal of Service Research, vol. 10, 318-334, May (2008)

23. L. G. Zomerdijk and C. A. Voss, "Service design for experience-centric services," Journal of Service Research vol. 13, issue 1, 67-82 (2010)

24. A. F. Payne, K. Storbacka and P. Frow, "Managing the co-creation of value," Journal of the Academy of Marketing Science, vol. 36, 83-96, (2008)

25. M. Stickdorn and J. Schneider, This is Service Design Thinking. BIS Publishers, The Netherlands, (2010)

26. C. A. Voss and J. Hsuan, "Service architecture and modularity," Decision Sciences, vol. 40, issue 3, 541-569 (2009)

27. S. K. Fixson, "Product architecture assessment: a tool to link product, process, and supply chain design decisions," Journal of Operations Management, vol. 23, issue 3/4, pp. 345-369, 2005.

28. A. V. Roth and L. J. Menor, "Insights into service operations management: a research agenda," Production and Operations Management, vol. 12, issue 2, 145-164 (2003)

29. TMF. Enhanced Telecom Operations Map (eTOM): The Business Process Framework, GB921, TeleManagement Forum Approved Version 4.0, March (2004)

30. E. K. Chew, "Service Science: A Reflection from Telecommunications Service Perspective." In Maglio P., Kieliszewski C., Spohrer J. (eds), Handbook of Service Science, Springer, New York, pp. 359-386, (2010)

31. S. L. Vargo and R. F. Lusch, "Evolving to a new dominant logic for marketing," Journal of Marketing, vol. 69, 1-17, January (2004)

32. S. L. Vargo and R. F. Lusch, "Service-dominant logic: continuing the evolution," Journal of the Academy of Marketing Science, vol. 36, 1-10 (2008)

33. E. J. Arnould, "Service-dominant logic and resource theory," Journal of the Academy of Marketing Science, vol. 36, 21-24 (2008)

34. F. Gallouj, "Innovation in the service economy: the new wealth of nations," Cheltenham, UK: Edward Elgar, (2002)

35. J. Gadrey and F. Gallouj, Productivity, Innovation and Knowledge in Services: New Economic and Socio-economic Approaches. Edward Elgar Publishing, Cheltenham, UK, (2002)

36. J. Spohrer, P. P. Maglio, J. Bailey and D. Gruhl, "Steps toward a science of service systems," IEEE Computer, 71-77, Jan (2007) 
37. P. P. Maglio, S. L. Vargo, N. Caswell and J. Spohrer, "The service system is the basic abstraction of service science," Information Systems E-Business Management, Springer Online Publication, (2009)

38. R. Normann and R. Ramirez, "From value chain to value constellation: designing interactive strategy," Harvard Business Review, vol. 71, 65-77, July-August, (1993)

39. R. F. Lusch, S. L. Vargo and M. O'Brien, "Competing through service: insights from service dominant logic,” Journal of Retailing, vol. 83, 5 - 18, January (2007)

40. J. A. Johannessen and B. Olsen, "The future of value creation and innovations: aspects of a theory of value creation and innovation in a global knowledge economy," International Journal of Information Management vol. 30, 502-511 (2010)

41. H. Chesbrough and A. Davies, "Advancing service innovations," in P. P Maglio, Kieliszewski and J. C. Spohrer (Eds.), Handbook of Service Science, Springer New York, pp. 579-601, (2010)

42. D. J. Teece, "Explicating dynamic capabilities: the nature and microfoundations of (sustainable) enterprise performance," Strategic Management Journal, vol. 28, 1319-1350 (2007)

43. B. Edvardsson, A. Gustafsson and J. Roos, I. (2005), "Service portraits in service research: a critical review," International Journal of Service Industry Management, vol. 16, issue 1, 107-121 (2005)

44. C. K. Prahalad and Ramaswamy, "Co-opting customer competence," Harvard Business Review, vol. 78 issue $1,79-87(2000)$

45. 45 E. Von Hippel, "Perspective: user toolkits for innovation," The Journal of Product Innovation Management, vol. 18, 247-257 (2001)

46. J. L. Heskett, T. O. Jones, G. W. Loveman, W. E. Sasser and L. A. Schlesinger, "Putting the serviceprofit chain to work," Harvard Business Review, 118-129, July-August, (2008)

47. C. M. Froehle and A. Roth, "New measurement scales for evaluating perceptions of the technologymediated customer service experience," Journal of Operations Management vol. 22, issue 1, 1-22, (2004)

48. M. Xue and P. T. Harker, "Customer efficiency: Concept and its impact on e-business management," Journal of Service Research, vol. 4, issue 2, 253-267 (2002)

49. S. L. Vargo, P. P. Maglio and M. A. Akaka, "On value and value co-creation: a service systems and service logic perspective,” European Management Journal vol. 26, 145-152 (2008)

50. A. Rawson, E. Duncan and C. Jones. The truth about customer experience. Harvard Business Review, $91(9), 91-98$ (2013)

51. M. Treacy and F. Wiersema, The Discipline of Market Leaders. Cambridge, Mass. Perseus Books, (1995)

52. C. Shaw, The DNA of Customer Experience: How Emotions Drive Value. Palgrave Macmillan, (2007)

53. R.S. Kaplan and D.P. Norton, Strategy Maps. Boston, MA: Harvard Business School Press, (2004)

54. J. C. Anderson, J. A. Narus and W. van Rossum, Customer Value Propositions in Business Markets, Harvard Business Review, March, 91-99 (2006) 